\title{
The study of Accountants Perceptions of Different Security Systems Adopted in the Public Accounting Sector in Lebanon
}

\author{
Ali KASSEM \\ The Bucharest University of Economic Studies, Bucharest, Romania \\ alikassem.finance@gmail.com \\ Bogdan Stefan IONESCU \\ The Bucharest University of Economic Studies, Bucharest, Romania \\ ionescub@gmail.com
}

\begin{abstract}
Public Accounting is one of the very rising sectors in the industry. The aim is to produce bulk of financial information that can be further used for making informed decisions by the stakeholders. The wrong information or might jeopardize the involved businesses and thus it is necessary to protect this sort of information from outside and vulnerable attacks. As, the transparency and accountability of financial statement is very crucial for the stakeholder's trust as well as the investment, the security of financial information is very essential for the relevance, validity, and reliability of the financial data. However, there is always a lingering risk of security breaches such as brute force attacks to get the information. The main focus of this paper is to examine the security systems and the strategies used by the public accountants in Lebanon to secure the financial data and relevance of financial reports. To carry out this study a quantitative methodology was applied and a survey was conducted with a representative sample of accountants, who are currently employed in the Lebanese governmental sector. The survey questionnaire was prepared to measure their perceptions regarding the security of the public accounting in Lebanon and to also evaluate their efficiency in protecting the data as well as detecting threats. The research conducted is likely to determine the quality of financial data protection in public accounting in Lebanon and suggest possible solutions in increasing security. As, the security measures are an integral part of the IPSAS implementation process this study highly contributes to both the theory of the IPSAS adoption and the practice of aligning local accounting practices in accordance to the international standards by doing exorbitant efforts to strengthen the security management in Lebanon's Public Accounting Sector.
\end{abstract}

Keywords: Information security, security protection, information leakages, public accounting, IPSAS, IPSAS implementation, Lebanon.

\section{Introduction}

Information technology (IT) has an increased influenced on almost all the government and private sectors in the recent years. Undoubtedly, it has also played a very crucial role in the services provided by the public accounting industry across the globe. However, there is no empirical research that has been specifically done to evaluate the impacts of information technology on the public accounting firms. Though, in order to make efficient use of information technology in the public sector there is a dire need of evaluating it and hence this research focuses on the different security systems that are currently adopted in the public accounting sector in Lebanon.

The study will mainly focus on the firms and office, where recently large IT investments were made, primarily in the audit software and the knowledge sharing applications. The quantitative information from the research will be analyzed to estimate the 
accountant's perception of different security systems and how efficient they are in detecting the threats and preventing it. The results from the analysis will indicate the significant steps that are to be taken to strengthen the IT implementation in public accounting sectors (Banker, Chang, \& Kao, 2002).

The advances in the field of information technology had a huge impact on many firms in the professional services industries of Lebanon, but perhaps the public accounting industry is the one to worry about. The public accounting industry was once considered as a slow paced and a very conservative industry, however in recent years this industry has undergone incredible changes at the turn of the era, glinted with the rapid changes in its technological environment (Elliott, 1998). The audit software as well as the other knowledge sharing applications are the most critical components of these changes. The mechanization of the audit tasks and the use of audit software has replaced IT for the manual labor and thus the structure of the audit teams changed consequently.

Another important use of information technology in public accounting is to maneuver the advanced systems and to get the useful as well as shared knowledge from different parts of the organization. This use of information technology has enabled the professional services that can be leveraged effectively by the human resources (Gogan, Applegate, \& Nolan, 1995). Thus, with the rapid use of information technology, various researches have been conducted in the area of practitioner-oriented accounting, which discuss how to prevent the security breaches in current technology (Smith, 1997). In order to justify the use of IT in public accounting, the managers need to understand the potential benefits resulting from the investment and how these benefits can be manipulated with a typical security breach.

Though, there is a general perception of accountants that the use of information technology in public accounting can improve the firm's productivity, but they are ignorant to the fact that its use also triggers numerous vulnerabilities that are to be taken care of. The impact of IT on the firm's performance cannot be evaluated directly. The public accounting firms need to understand the threat to the information and how it can be encountered. The technology can certainly transform their work, but whether such transformation leads to productivity gain or not is dependent on the system's security (Lee \& Arentzoff, 1991).

The longitudinal analysis before and after implementation of information technology is an important task to support the causality argument, which leading from IT deployment to its improvement for the firm's productivity. This is especially essential for the public accounting firm, where the use of information is one of the core competences. The aim of this research is to evaluate the accountant's perceptions on the adopted security system in Lebanon's public accounting sectors. By doing this, it can be determined that how a security breach or the improper use of a security system can impact the productivity of a public accounting firm. The empirical results from the surveys conducted in this research indicated a significant need to improve the implementation of IT security systems (Zarowin, 1994).

\section{Literature review}

Since the tremendous use of Information technology, a lot of theories have been worked upon and exhausted to study the challenges of adopting a Computerized Accounting Systems 
(CAS). Not only that but numerous technology acceptance model (TAM) were developed to automate the system and to make it much more efficient. Some of the very famous models are the Roger's Diffusion of Innovation (DoI) model and the unified technology acceptance user theory (UTAUT) (Venkatesh, et al 2003). The Technology Acceptance Model has proven to be a very effective information systems model that has been accepted by the users.

However, any model that has been developed and is presented to the users there are two very important factors that must be heeded to. These factors are inclusive of the decision-making skills of the users about how and when they need to take the specific action. The success of any theoretical model is totally dependent on its ability to cope up in the time of crisis and to hold a secure front. Though, it is also necessary for the users to understand and the behavior of the system even before its implementation. Various models when tested usually fails to provide the required security (Juiz, Guerrero, \& Lera, 2014).

For the very first time the threat to the accounting firms was realized in 2013, when about 900 of the Connecticut residents in the Fairfield County found out that the small-town accounting firm has become a prime target for the hackers and in an aftermath the tax returns were stolen directly from the firm's computers. The hacking scheme was very turbulent, yet very cleverly the selected returns that were completed but not filed were altered and then sent to the IRS in hopes of collecting the refunds even before the legitimate filers could find out about it. This incident made it clear that even the small public accounting firms are exposed to the risk of information theft and manipulation.

Though, the stolen tax returns might seem nothing but the expanse of personal information amassed by the CPA firms about the clients over many years, when leaked can be very overwhelming. This staggering information in the hands of a cybercriminal, might lead to a bigger damage inclusive of the fraud, identity theft and even the theft of tangible property. Thus, from the very smaller public accounting firms that works with the individuals as well as with the small business clients, to the international CPA firms that offers services to the world's renowned and magnanimous corporations the accounting practices of all streaks and of all sizes should take major steps in educating the accountants about cybersecurity and familiarizing them with the systems vulnerabilities (CIPFA \& IFAC, 2013).

Various information technology models developed for the public accounting sectors are codependent on the security audits that improves the system compliance and can also benefit in long run. The cybersecurity professionals are now working with the accounting professionals to find the ways of preventing all sort of security threats to the data. The identify issues are dealt by using the same traditional techniques that accountants used with their clients.

The system security audits became the ground zero for preventing the vulnerable threats to the data. However, these audits are very much similar to the traditional financial audits, yet it is automated. All the checks require minimum time of the accountants, while they go through the configuration details as well as keep track of the logs and records. All the activities must then be compared to the recommended and the required settings. In case of malfunctioning, it must be reported to the notice of offending parties for correction.

This is by far the accepted model of the cybersecurity, yet an orderly and a very effective procedure that fits perfectly to the regular practices of an accounting firms. Though, a recent survey of Association for Chartered Certified Accountants (ACCA) indicated that nearly half of the member of the firms periodically opts to engage in the information system 
security audits. Thus, this lack of concern might be damaging to the firm itself. The ACCA has thus advised the accountants to work in collaboration with the cybersecurity professionals as well as with the other professional services to enhance the security posture of a firm.

Since the high security risk to the public accounting firms, the ACCA is currently working with the ISACA (Information Systems Audit and Control Association), which also a non-profit organization that supports the information systems security professionals and educate the ACCA members about the cybersecurity administration, analysis, audits as well as with the system structure (Brecht \& Martin, 2006).

The Journal of Accountancy in 2015 conducted an interview with the three technology focused CPAs. In an interview the state of the accounting industry was clearly depicted, where it was also mentioned that the accountants, who give no importance to the system security gives no importance to the system architecture as well. Most accountants have a perception that the cybersecurity policies are only applied just in the office, thus they seem really confused on the prospect of the applications and services that are cloud-based. This is due to their unfamiliarity with the system's security features, which might pose a threat to the data. Thus, overcoming all the knowledge gaps regarding the cybersecurity is important for the accountants before they even familiarize themselves with the system.

Undoubtedly, some of the smaller firms have also become aware of the security threats and the risks. Even the Lebanese Government have made vigorous efforts to align the corporate financial reporting requirements and has made an effort to work with the International Accounting Standards (IAS). The IAS has been accepted as an international standard to be followed in all the financial statements in Lebanon. Moreover, a lot of effort is made to produce the high-quality financial reporting for the public interest entities, so that they can make an informed decision (Juiz, Guerrero, \& Lera, 2014).

While IAS is an adaptive system but it is much more complicated than the small and medium size enterprise and despite implementing the international standards, there still are the loopholes and the compliance gaps of varying degrees in both the auditing and accounting practices in the firms. Though, a very minimal gap or a loophole is enlisted in the companies and the banks, but a greater gap is noticed in the public accounting firms and other companies. These loopholes are primarily due to the shortcomings in the professional education and practices in Lebanon.

The main reason of this shortcoming was that when the Lebanese Association for Certified Public Accountants was established in the year 1994, the applicants who were offered a license to practice, were certified even without an examination. Also, there was no such enforcement mechanism to ensure the IAS compliance for the accountants.

In a survey conducted in 2014 by the Accounting Web, about 65 percent of the accountants indicated that the cyber threat level is high or increasing and only 14 percent of then gave an indication that they were directly involved in securing the information from vulnerabilities and other cyber threats. This pose a serious challenge for the cybersecurity professionals to overcome their shortcomings. Undoubtedly, in accounting it is a professional tribute to rigidly adhere to the rules and the formats that can be altered with time, but it can be a very challenging task to convince the CPAs as well as the firm executives to constantly update the security protocols in response to the new threats. Thus, the accounting firms becomes an easy pick for the hackers.

Though, with the target on their backs, of course the huge accounting, auditing, and other professional services inclusive of finance have exerted an ample amount of resources 
to strengthen their system's security as well as improve its architecture to prevent an impulsive and massive cyber thefts. But the smaller local accounting firms are not prudent enough to adapt the security system. The hackers always target the path of least resistance and the smaller firms are much of the listed target. Also, the access to information is very easy in the tax returns, bank statements, and other legal documents (Rahman, Msadek, Jaoude, \& Gielen, 2003 ).

PICBE | 339

Undoubtedly, the number of small-scale accounting firms is infinitesimally small in comparison to the other massive international professional services firms or the regional CPA firms. Therefore, there is a high risk of security threat and it could easily lead to the false sense of security. A lot of accountants have a perception that if there is no attention paid to their data the chances are that it won't be hacked. Though, this approach is untrue for the high-speed world of the Internet. It becomes very easy for the hackers to scan numerous smaller networks rather than scanning a few larger networks.

Moreover, the extent to which these threats have become automated is very shocking and has become very challenging to the information security. But all these threats can be resolved proactively, if the vulnerabilities are detected quickly and preventive steps are taken as recommended by the network administrator. The complacency and the rigidity of the system are also difficult problems that needed to be taken care of. Usually, when a market pressures increased the public accounting sector is exposed much more to these vulnerabilities and then even a small glitch causes a fortune (Juiz, Guerrero, \& Lera, 2014).

The public accounting sector also allows a consumer and an accountant to connect and interact online for various decision-making advices. Consequently, there is also an involvement of the legal documents of a consumer, when these documents are submitted online, it becomes a vulnerability. Also, the use of electronic signature has increased the risk of threat to any firm. As the accounting firms take upon all the pressure of implementing the security within the systems, they sometimes do run the risk of creating more loopholes that can be further exploited.

The use of client portals and the quick deployment of the sensitive information through the contracts can rife up the vulnerability factor of an information security system. If this exploitation in the public relations sector hitting the accounting firms is not an enough motivation for the accountants, then a hit to the bottom line will be. According to the Accounting Today, most of the CPA firms are legally accountable to the Government for exposing the customer data because of a vulnerability (CIPFA \& IFAC, 2013).

Moreover, the firms that still do not rely on the expertise of a cybersecurity experts are accountable to answer under a barrage of civil claims as well as the government sanctions. Also, it has become mandatory for all the accountants and professionals in the accounting industry to allocate their major resources to the structure of cybersecurity system and even have a dedicated in-house team or a contracting party with respected expertise in the field of cybersecurity (Banker, Chang, \& Kao, 2002).

\section{Methodology}

This research was guided by the quantitative methodology and is characterized by testing the validity of theory on the basis of the results generated. According to the literature review the extent and impact of cyber security in the accounting practice of public institutions is dependent on various factors inclusive of the size of the organization, qualifications of the 
accountants, training on the use of secure systems, level of awareness, availability of the resources, audit and compliance in accordance to the policies (Brecht \& Martin, 2006).

Moreover, the efficiency of the security systems is also co-dependent on the accounting practices. However, there are some accountants who still presume that a vulnerable attack on the information or data set is minimal in the public accounting sector. The quantitative analysis will allow the research to be conducted on a population that connotes an entire group of individuals, events or objects having a common, yet observable characteristic.

The data is collected using a questionnaire that was prepared to conduct this research (See Appendix I). The reason to use a questionnaire is that it covers large sample at a very low cost. However, a questionnaire is also disadvantageous because firstly it may have a low response rate, a situation whereby some of the respondents may not be willing to fill the questionnaires. Secondly, questionnaires may bring along uncontentious and dishonest replies where the target population may give wrong responses regarding the topic questions. Finally, the questionnaires lack personalization hence hidden agendas that maybe expressed through facial gestures and expressions may not be simple to realize. However, in our case, the response from the questionnaire was obtained, sampled and recorded. The sample allows to collect response from a smaller group of accountants that truly represents the bigger part of the population working in the Lebanon public accounting sector.

\section{Results and discussions}

The Survey questionnaire respondents were 100, who either worked in financial firms or in Lebanese financial government agency. The questionnaire was drafted in accordance with the research scopes. In order to evaluate the responses SPSS was used and the following graphs depicts the responses of a population representing the accountants working in the financial firms of Lebanon.

Figure 1. A Graph of use of security system against accountants.

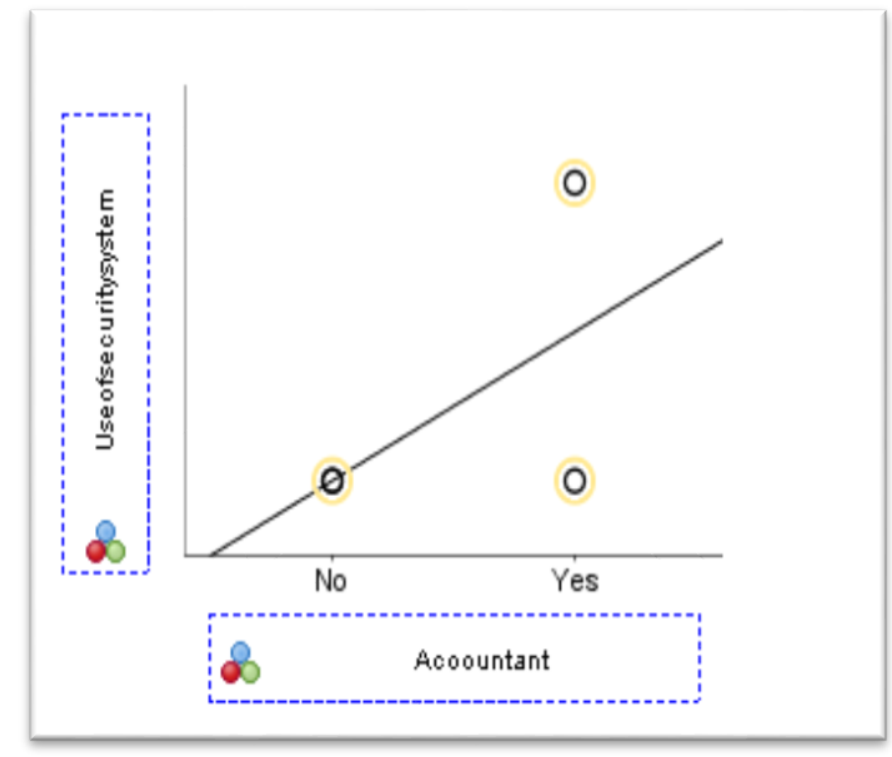

Source: Author's own research 
In this scattered plot it can be seen that the majority accountants agreed on the fact that their firms use Security systems when it comes to sensitive data in public sectors. This prevents the data from falling into the hands of hackers and thus prevent loss or damage of information through cyber robbery. Furthermore, secured data lowers operational costs that might result from high expenses that might be incurred in case a security is bypassed. The so saved cost maybe used to develop more complex security authentications that will also reduce development and support time. However, there are still a number of firms that do not take steps to secure the public information, though the number is small, but it is quite alarming. These firms tend to always be at risk of robbery and cyber terrorism, which may in return turn to them incurring high costs in case of an incident.

Figure 2. A Graph plot of security concerns against the accountants.

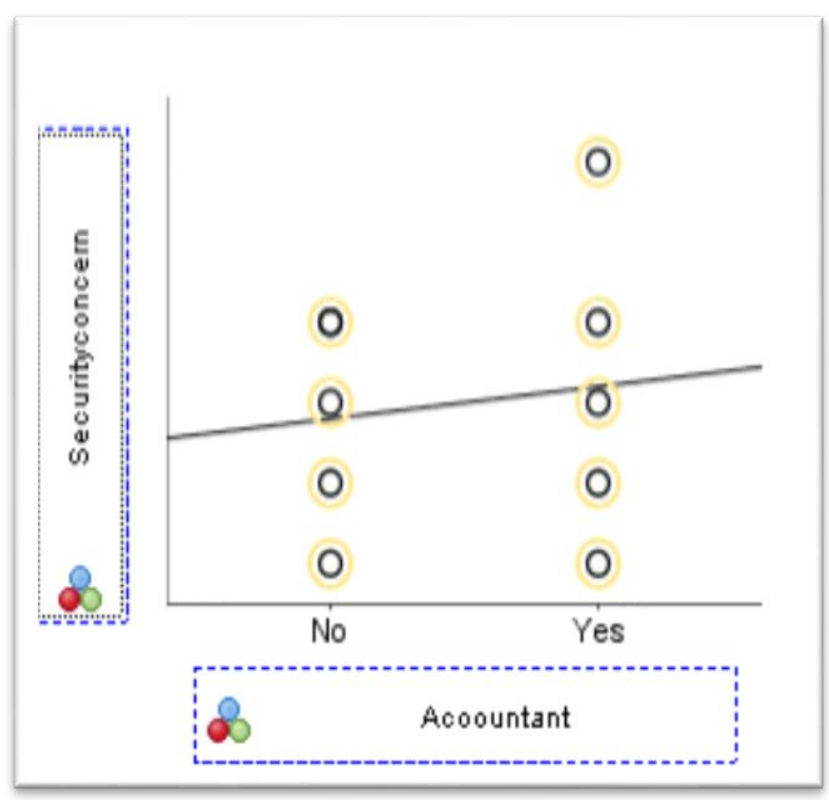

Source: Author's own research

Though the firms take duly notice of the prevailing security concern and work towards making it efficient. However, out of 100 only 59 respondents agreed that their firms take serious notice of all the security concerns and thus due to this there is a disturbing record of data leakage incidence within the firm.

According to the survey conducted, only $34 \%$ agreed upon the fact that the data leakage incidence is low in their organization, whereas $32 \%$ disagreed on the fact that the data leakage percentage is less. The remainder percentage of the respondents were neutral as depicted in the graph. 
Figure 3. A Graph Illustrating the Population of Accountants Experiencing Data Leakage Incidence.

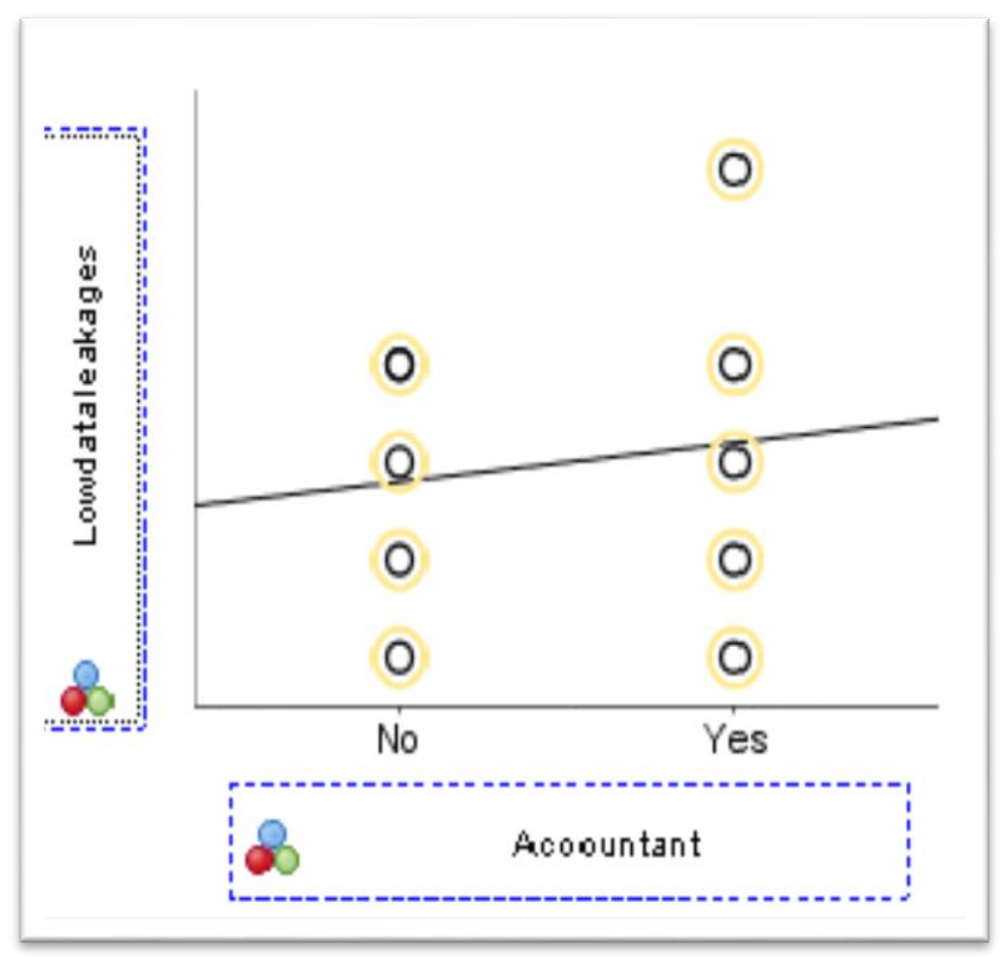

PICBE $\mid 342$

\section{Conclusion}

Source: Author's own research

The research concludes that though the automation of processes in public accounting firm has benefitted a lot, but there is a lingering threat of security risks that needs to be taken care of. Lebanon has become very efficient in public accounting sector in the recent few years, though there is still a need to educate the Lebanese accountants, where information security is concerned.

The computerized accounting information system that is used by the executives' officers of government's ministries or in the departments as well as agencies have an ample amount of sensitive data that needs a proper security structure to remain unscathed. A lot of automated accounting models are proposed by the researchers that can prove to be very effective, though the implementation of such model requires a proper training that must be offered to the accountants.

The information and communication technology (ICT) have undoubtedly transformed the firms in the professional arena, but only few accountants in the public accounting sector heed much to it. Thus, in the Lebanon public accounting sector there is a need to undergo a tremendous change at the turn of this millennium, sparked largely by the potential security threats that prevails in the world of Information Technology.

This study aided in finding out the loopholes that hinder the implementation of security within the system. Though, the government is working towards making its system efficient enough, but there is a lack of proper training and education in the accounting sector in regards to the information security structure. This issue causes a challenge for the public sectors to excel and improve in the future. 


\section{References}

Applegate, L. (2019). Lynda M. Applegate - Faculty \& Research - Harvard Business School. Retrieved from https://www.hbs.edu/faculty/Pages/print-profile.aspx?facId=6411

Banker, R. D., Hsihui Chang, \& Yi-ching Kao. (2002). Impact of Information Technology on Public Accounting Firm Productivity. Journal of Information Systems, 16(2), 209222. https://doi.org/10.2308/jis.2002.16.2.209

Brecht, H. D., \& Martin, M. P. (1996). Accounting Information Systems: The Challenge of Extending Their Scope to Business and Information Strategy. Accounting Horizons, 10(4), 16-22. Retrieved from http://165.193.178.96/login?url=http\%3a\%2f\%2fsearch.ebscohost.com\%2flogin.a spx\%3fdirect\%3dtrue\%26db\%3dbth\%26AN\%3d9707141997\%26site\%3deds-live

CIPFA, \& IFAC. (2013). Good Governance in the Public Sector-Consultation Draft for an International Framework. Retrieved from http://www.ifac.org/system/files/publications/files/Good-Governance-in-thePublic-Sector.pdf

Elliott, R. K. (2000). Who Are We As a Profession--and What Must We Become? Journal of Accountancy, 189(2), 81-85. Retrieved from http://165.193.178.96/login?url=http\%3a\%2f\%2fsearch.ebscohost.com\%2flogin.a spx\%3fdirect\%3dtrue\%26db\%3dbth\%26AN\%3d2761270\%26site\%3deds-live.

Juiz, C., Guerrero, C., \& Lera, I. (2014).Implementing Good Governance Principles for the Public Sector in Information Technology Governance Frameworks.. [online] Ifac.org. Available at: http://www.ifac.org/system/files/publications/files/GoodGovernance-in-the-Public-Sector.pdf.

Lee, J. Y., \& Arentzoff, S. (1991). The productivity factor: justifying your computer purchase. - Free Online Library. [online] Available at: https://www.thefreelibrary.com/The+productivity+factor\%3a+justifying+your+co mputer+purchase.-a010737508

Rahman, M. Z., Msadek, S., Jaoude, R. B., \& Gielen, F. (2003 ). . Retrieved from https://openknowledge.worldbank.org/bitstream/handle/10986/14484/350940L EB0Accounting0rosc1aa1lbn.pdf?sequence=1\&isAllowed=y

Smith, S. (1997). The smart way to invest in computers. Journal of Accountancy, 183(5), 63-65. Retrieved from http://165.193.178.96/login?url=http\%3a\%2f\%2fsearch.ebscohost.com\%2flogin.a spx\%3fdirect\%3dtrue\%26db\%3dbth\%26AN\%3d9708190500\%26site\%3deds-live

Zarowin, S. (1994). The Computer as Communicator. Journal of Accountancy, 177(4), 3742. Retrieved from http://165.193.178.96/login?url=http\%3a\%2f\%2fsearch.ebscohost.com\%2flogin.a spx\%3fdirect\%3dtrue\%26db\%3dbth\%26AN\%3d9407210554\%26site\% 


\section{Appendix I}

Dear Respondents!

This study aims at examining security systems and strategies used by public accountants in Lebanon to protect financial data and relevance of financial reports. You will be asked to complete the survey form to help determine the quality of financial data PICBE | 344

protection in public accounting in Lebanon and suggest possible solutions in increasing security. At the start, you are asked for some pre-qualifying information as well.

Your participation is voluntary and confidential. You may not return the completed survey if you do not want to participate.

SECTION 1: PRE-QUALIFYING INFORMATION.

Please, answer the following questions choosing either "yes" or "no" option

1. Are you occupying a position in the accounting or finance department of a government agency in Lebanon?

Yes/No

2. Are you responsible for collecting financial data and preparing financial reports for a Lebanese government agency?

Yes/No

3. Do you use any security systems and strategies in your work to protect financial data and relevance of financial report?

Yes/No

\section{SECTION 2: DEMOGRAPHIC DATA.}

Please, answer the following questions choosing one of answer options

1. What is your educational level?
a. College diploma
b. Bachelor's degree
c. Master's degree
d. Ph.D.

2. What is your age?
a. 20-30 years
b. 31-40 years
c. 42-50 years
d. 51 years and above

3. What is your gender?
a. Female
b. Male 
SECTION 3: THE USE OF SECURITY SYSTEMS AND STRATEGIES

A- Please, rate your answers below in correspondence with the following meanings:

$1=$ Strongly disagree

$2=$ Disagree

$3=$ Neutral

$4=$ Agree

5 = Strongly agree

\begin{tabular}{|c|c|c|c|c|c|c|}
\hline & & 1 & 2 & 3 & 4 & 5 \\
\hline 1 & $\begin{array}{l}\text { There is a strong security concern in our } \\
\text { organization. }\end{array}$ & & & & & \\
\hline 2 & $\begin{array}{l}\text { Effective physical and digital security measures } \\
\text { are in place in our organization. }\end{array}$ & & & & & \\
\hline 3 & $\begin{array}{l}\text { Does a strong firewall scans the incoming and } \\
\text { outgoing network traffic of our organization? }\end{array}$ & & & & & \\
\hline 4 & $\begin{array}{l}\text { All computers and digital devices have the } \\
\text { installed antivirus protection. }\end{array}$ & & & & & \\
\hline 5 & $\begin{array}{l}\text { The incidence of data leakages is low in our } \\
\text { organization. }\end{array}$ & & & & & \\
\hline 6 & $\begin{array}{l}\text { The organization practices employee training in } \\
\text { security measures. }\end{array}$ & & & & & \\
\hline 7 & $\begin{array}{l}\text { We have control mechanisms for data flows } \\
\text { within the organization and beyond its physical } \\
\text { boundaries. . }\end{array}$ & & & & & \\
\hline
\end{tabular}

B- on a scale of 1-10, 1 being very poor and 10 being very good, how would you rate of each of the following:

\begin{tabular}{|l|l|l|l|l|l|l|l|l|l|l|l|}
\hline Q1 & $\begin{array}{l}\text { Specify the (weight) of important } \\
\text { information Security factor to accounting } \\
\text { information systems? }\end{array}$ & 1 & 2 & 3 & 4 & 5 & 6 & 7 & 8 & 9 & 10 \\
\hline 1 & $\begin{array}{l}\text { In day-to-day business operations } \\
\text { (document collection, transaction } \\
\text { processing, banking,billing, expenses, } \\
\text { etc.) }\end{array}$ & & & & & & & & & & \\
\hline 2 & $\begin{array}{l}\text { In financial reports (monthly closed, } \\
\text { financial statements) }\end{array}$ & & & & & & & & & \\
\hline 3 & internal cotrol. & & & & & & & & & & \\
\hline 4 & Audit & & & & & & & & & & \\
\hline 5 & Make payments online & & & & & & & & & & \\
\hline 6 & E.mail. & & & & & & & & & \\
\hline
\end{tabular}




\begin{tabular}{|l|l|l|l|l|l|l|l|l|l|l|l|}
\hline 7 & Storage of documents & & & & & & & & & & \\
\hline 8 & Web Application & & & & & & & & & & \\
\hline 9 & Other (please specify) & & & & & & & & \\
\hline Q2 & $\begin{array}{l}\text { Evaluate the limitations of implementing } \\
\text { data security controls in information } \\
\text { technology with accounting } \\
\text { implications? }\end{array}$ & & & & & & & & & \\
\hline 1 & Loss of control over data and systems & & & & & & & & & & \\
\hline 2 & Access to information & & & & & & & & & & \\
\hline 3 & $\begin{array}{l}\text { A complex and difficult process has been } \\
\text { put in place }\end{array}$ & & & & & & & & & & \\
\hline 4 & fees, costs & & & & & & & & & \\
\hline 5 & $\begin{array}{l}\text { Intellectual property rights (legal } \\
\text { framework). }\end{array}$ & & & & & & & & & & \\
\hline 6 & others & & & & & & & & & & \\
\hline
\end{tabular}

C- Please, answer the following with: YES, NO, NO Answer (N/A)

\begin{tabular}{|l|l|l|l|l|}
\hline & & YES & NO & N/A \\
\hline 1 & $\begin{array}{l}\text { Our financial systems use two-factor authentication } \\
\text { systems measures }\end{array}$ & & & \\
\hline 2 & Our systems are protected via multiple authentication & & & \\
\hline 3 & $\begin{array}{l}\text { Technical staff accounts for regular update of systems and } \\
\text { programs }\end{array}$ & & & \\
\hline 4 & Our programs are regularly upgraded & & & \\
\hline 5 & We use encryption to protect laptops & & \\
\hline 6 & $\begin{array}{l}\text { Personal smartphones of accounting staff have installed } \\
\text { encryption software }\end{array}$ & & & \\
\hline 7 & We conduct backup investigations monthly & & \\
\hline
\end{tabular}

\section{Thank you for your time and participation!}

